\title{
Endoscopic transoral resection of an elongated styloid process: a case report
}

\author{
Shilpa H. ${ }^{1}$, Amrita Suzanne Mathew ${ }^{1 *}$, Sandhya Hemraj ${ }^{2}$, Aishwarya Sridhar ${ }^{1}$
}

\author{
${ }^{1}$ Department of Otorhinolaryngology, ${ }^{2}$ Department of Radiology, MVJ Medical College and Research Hospital, \\ Bangalore, Karnataka, India
}

Received: 09 July 2018

Accepted: 08 August 2018

\section{*Correspondence:}

Dr. Amrita Suzanne Mathew,

E-mail: amritasmathew@gmail.com

Copyright: (C) the author(s), publisher and licensee Medip Academy. This is an open-access article distributed under the terms of the Creative Commons Attribution Non-Commercial License, which permits unrestricted non-commercial use, distribution, and reproduction in any medium, provided the original work is properly cited.

\begin{abstract}
Eagle's syndrome is an aggregate of craniocervicofacial symptoms due to an elongated styloid process/calcified stylohyoid ligament. Adequate history, clinical and radiological examination, and sound knowledge of mimicking pathology can help in its diagnosis. Computerised tomography (CT) with 3D reconstruction is the most accurate investigation currently available. Treatment can be either surgical or non-surgical. Surgical excision of the abnormally elongated styloid process is preferred. Extraoral and intraoral approaches are available, each with their inherent advantages/disadvantages. Endoscope-assisted transoral resection resolves the disadvantages associated with the latter, representing a favourable advancement. We report a case who presented with craniocervicofacial pain, diagnosed clinically and on 3D-CT with Eagle's Syndrome, and treated successfully by endoscope-assisted transoral resection.
\end{abstract}

Keywords: Eagle’s syndrome, Endoscopy/methods, X-ray computed

\section{INTRODUCTION}

Eagle's syndrome/elongated styloid process, is a condition that may be the source of craniofacial and cervical pain. It occurs when either the total length of the styloid process is longer than $25 \mathrm{~mm}$, or when stylohyoid/stylomandibular ligaments are ossified. ${ }^{1}$ Although approximately $4 \%$ of the population is thought to have an elongated styloid process, only between $4 \%$ and $10.3 \%$ of this group is symptomatic. ${ }^{2}$ Therefore,the actual incidence of Eagle's syndrome is $0.16 \%{ }^{3}$

With symptoms alone, diagnostic difficulties exist due to the existence of various other diseases with similar presentations. $^{4}$ Diagnosis is made by physical examination and is confirmed radiographically using panoramic radiographs, skull posterior-anterior conventional $\mathrm{x}$-ray or computerised tomography $(\mathrm{CT}) .^{2,4,5}$ Currently, CT is the standard method for diagnosis. ${ }^{6,7}$
Treatment of Eagle's syndrome is both surgical and nonsurgical. ${ }^{2}$ Even though medical treatment using analgesic or local steroid injection is an option, the condition is not proven to be well treated/resolved. It is generally accepted that surgical resection of elongated styloid process is the primary treatment for Eagle's Syndrome. The two surgical approaches are transoral/transpharyngeal and external/transcervical. ${ }^{3}$ The extra oral approach has a lower risk of deep space neck infection, with better visualization of the surgical field. The transpharyngeal approach avoids external scarring, but has been criticized due to increased risk of deep space neck infection and poor visualization of the surgical field. ${ }^{2}$ However, endoscopy-assisted transoral resection resolves this disadvantage. ${ }^{8}$

We report a case of a middle aged female who after having consulted numerous clinicians, presented to us with unrelenting craniocervicofacial pain for the past two 
years which was diagnosed by us on examination and 3D-CT as an elongated styloid process, and treated using endoscope-assisted transoral resection, with a successful outcome.

\section{CASE REPORT}

A 45 year old female presented to the Department of Otorhinolaryngology, with the emphatically described complaints of right sided head, neck and shoulder pain for the past two years, which radiated to the right ear and its surrounding region, aggravated on turning/extending her neck. She also experienced foreign body sensation in the throat along with persistent throat pain, exacerbated by swallowing and chewing. Her past medical and surgical history was non-contributory. During this period, she consulted with several different medical specialists but experienced no relief/improvement. Various differential diagnosis were excluded during examination. On palpation of the right tonsillar fossa, a bony outgrowth was palpable, along with exacerbation of the pain. This finding was absent on the opposite side, leading to the diagnosis of an elongated right styloid process.

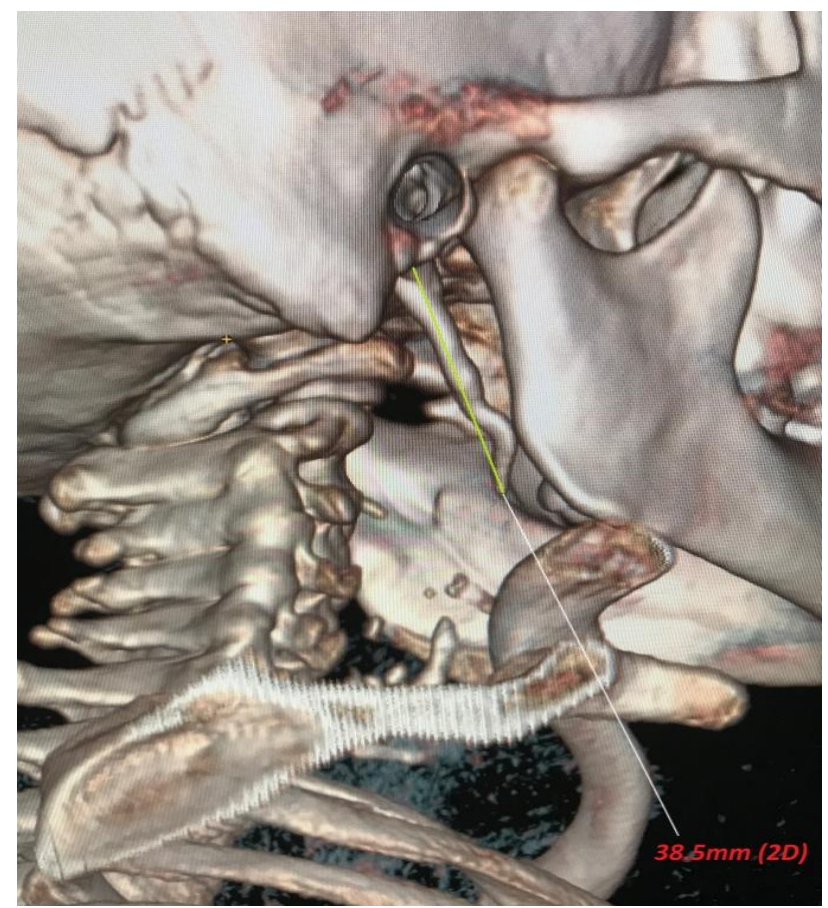

Figure 1: 3D CT showing an elongated right styloid process measuring $3.85 \mathrm{~cm}$.

CT/3D-CT confirmed the presence of an elongated (3.85 $\mathrm{cm})$ right styloid process with an ' $\mathrm{S}$ ' shaped bend and forward course towards the pharynx (Figure 1). Intraoral surgical treatment i.e. endoscope assisted right tonsillostyloidectomy was performed under general anaesthesia. Following tonsillectomy, the tip of the styloid process was identified by palpation. An endoscope was inserted orally, providing a magnified view of the surgical field. The fibres of the superior constrictor muscle were dissected, separated, and retracted. Periosteum at the tip of the styloid was incised and stripped off its distal third. $1 \mathrm{~cm}$ of this caudal part was excised (Figure 2) and the pharyngeal wall sutured with vicryl to protect the parapharyngeal space from sputum and food debris. The patient's symptoms regressed and she was discharged free of complaints on postoperative day 2. She remained asymptomatic on subsequent follow ups.

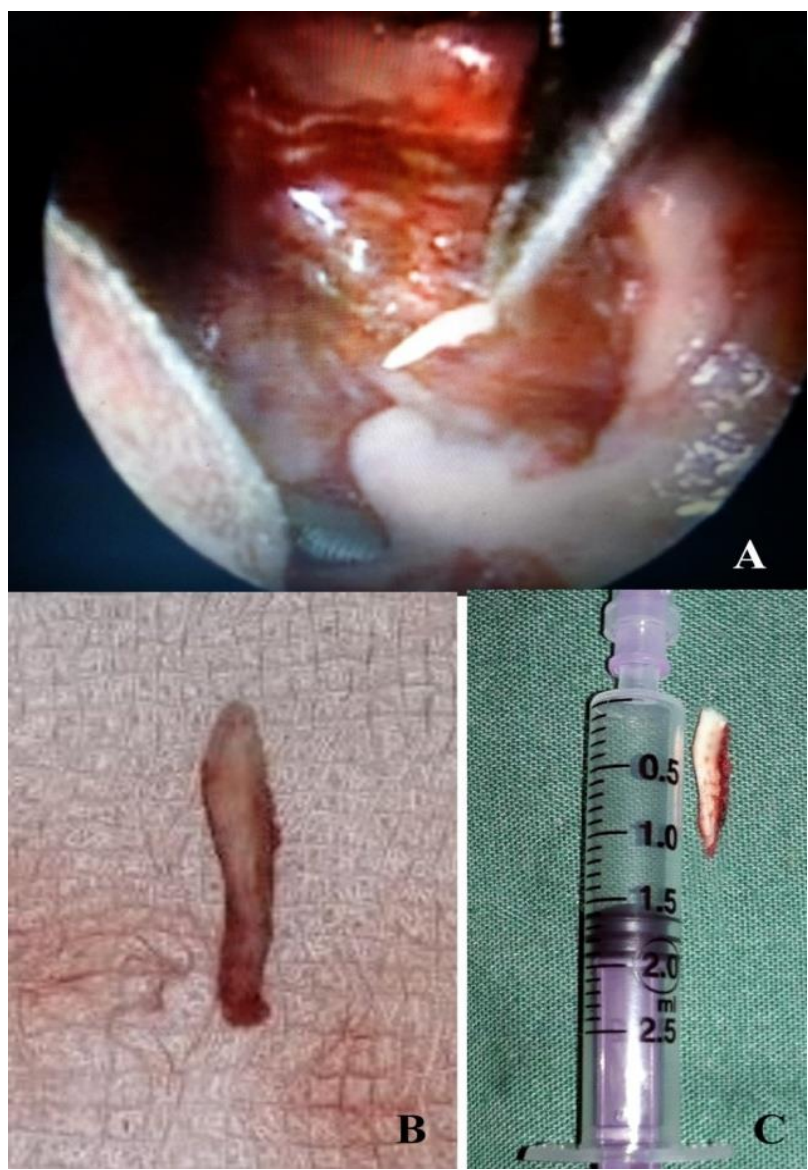

Figure 2: (A): Intraoperative endoscopic image showing excision of right styloid process transorally;

$(B, C)$ : Excised portion of right styloid process

following endoscope assisted transoral excision.

\section{DISCUSSION}

Eagle's syndrome or stylalgia, is a symptomatic, abnormally elongated styloid process and/or a calcification of the stylohyoid ligament. ${ }^{9}$ It is an uncommon and under diagnosed clinical entity affecting most commonly women in the $4^{\text {th }}$ to $6^{\text {th }}$ decade of life, as seen in our case. ${ }^{5}$

The stylohyoid complex consists of styloid process, stylohyoid ligament and lesser horn of hyoid bone, derived from $2^{\text {nd }}$ branchial arch of reichert cartilage. The styloid process is a slender outgrowth at the base of the temporal bone, to which are attached three muscles i.e. styloglossus, stylohyoid, stylopharyngeus and two 
ligaments i.e. stylohyoid and stylomandibular. ${ }^{5,3}$ The styloid process lies caudally, medially and anteriorly towards the maxillo-vertebro-pharyngeal recess [containing the external (ECA) and internal (ICA) carotid arteries between which the tip of the styloid process lies, the internal jugular vein, lower division of trigeminal nerve, the facial, glossopharyngeal, vagus and hypoglossal nerves]. ${ }^{10}$ The styloid process, when elongated, irritates these nerves and blood vessels, resulting in pain in the affected area. ${ }^{5}$

The most common presenting symptoms are persistent throat pain, foreign body sensation, dysphagia, odynophagia, chronic neck pain, headache and referred otalgia, all of which were present in our case. The exact mechanism leading to pain in Eagle's syndrome remains unclear but there are several hypotheses. ${ }^{3}$ First, 'classic styloid syndrome' is caused by stimulation of the $5^{\text {th }}, 7^{\text {th }}, 9^{\text {th }}$ and $10^{\text {th }}$ cranial nerves near the styloid process due to entrapment in locally formed scar tissue 2-12 months following tonsillectomy. This may damage surrounding soft tissue, causing ossification, leading to styloid process elongation and ossification of the stylohyoid ligament. It is characterized by isolated pharyngalgia in the tonsillar fossa, with dysphagia, odynophagia and a foreign body sensation in the pharynx. ${ }^{5}$

The second type is 'stylocarotid syndrome', due to direct mechanical irritation of sympathetic nerves accompanying the ICA/ECA within the carotid sheath. This may follow local inflammation/deposition of excess granulation tissue during healing of subclinical fractures due to head and neck trauma. Direct irritation produces pain that is referred along the distribution of the vessels involved. In ECA involvement, the patient may experience neck pain radiating to the eye, ear, mandible, soft palate and nose. Impingement upon the ICA causes parietal cephalalgia and pain along the distribution of the ophthalmic artery. ${ }^{11}$ Rarely, visual disturbances and syncopal episodes occur. ${ }^{4}$ Other hypothesized causes include inherited/familial disorder; congenital persistence of an embryological precursor; stimulation of surrounding nerves such as the terminal branches of the glossopharyngeal/trigeminal/chorda tympani nerves; insertion tendonitis of the stylohyoid ligament; ossification of the stylohyoid ligament in postmenopausal women; rheumatic styloiditis caused by pharyngeal infections, trauma and involutional changes associated with aging (e.g. degenerative cervical discopathy). 5,2,4,12,13

Due to its non-specific symptoms, patients with Eagle's syndrome seek treatment in various clinics such as otolaryngology, family practice, neurology, neurosurgery, psychiatry and dentistry, as had occurred in our case. ${ }^{8}$ An exhaustive differential diagnosis which includes various neuralgias, migraine/cervicogenic/ cluster/tension headache, temporomandibular joint disorders, impacted/ unerupted third molar, sialolithiasis, tonsillitis, otitis media, mastoiditis, foreign bodies, inflammatory/ neoplastic processes in the oropharyngeal/ esophageal areas and psychosomatic diseases have to be excluded before considering Eagle's syndrome. ${ }^{4,13}$ Palpation of the styloid process in the tonsillar fossa is indicative of elongated styloid since processes of normal length are not normally palpable. ${ }^{2}$ If pain is reproduced by palpation and either referred to the ear/face/head, the diagnosis of an elongated styloid process is very likely. ${ }^{13}$ These were the two clinching signs in favour of our diagnosis.

The diagnosis of elongated styloid process should be confirmed by imaging.,13 $\mathrm{CT}$ is the best and most accurate and is currently defined as the standard diagnostic method.,6,7 3D-CT, which was the imaging modality used in our case, is the most advanced diagnostic imaging technique to evaluate the stylohyoid chain, with accurate length measurements, direction and anatomical relations, allowing pre-operative planning, thereby reducing risk of intraoperative injury. ${ }^{4,10} 3 \mathrm{D}-\mathrm{CT}$ additionally helps the patient understand the abnormality and its treatment. However, 3D-CT has certain disadvantages, including image degradation with minimal movement, and a slightly higher radiation dose, depending on the number of sections taken. ${ }^{8}$

Radiographically, the accepted normal length of the styloid in an adult is approximately $2.5 \mathrm{~cm}$, whereas an elongated styloid is generally $3 \mathrm{~cm}$ in length. ${ }^{2}$ In our case, the right styloid process was $3.85 \mathrm{~cm}$. There is no correlation between degree of elongation of the styloid and severity of symptoms. Mere presence of an elongated styloid process is not pathognomonic for Eagle's syndrome because many patients with its incidental finding are asymptomatic. ${ }^{2}$ The variation of diversion of elongated styloid process may be the actual cause for symptoms. It can be either medial/lateral and anterior/posterior angulation, with anterior angulation being responsible for symptoms, as seen in our case. ${ }^{3}$

Management of this disease may be either non-surgical or surgical. Medical treatment consists of oral analgesics, antidepressants, anticonvulsants; steroid infiltration or repeated administration of local anaesthetics (1\% lidocaine/novocaine) into the tonsillar fossa. ${ }^{4,1}$ Other methods include pain reduction through physical therapy, relaxing muscles that had been constricted due to styloid process stimulation. ${ }^{4}$ It is purely symptomatic and has no long-term effectiveness. ${ }^{9}$

Surgical treatment remains the treatment of choice and consists of shortening of the elongated process by transtonsillar or external approaches which relieves symptoms. ${ }^{9,10}$ The choice of a specific surgical approach is highly variable and depends upon individual surgeon preference and experience. ${ }^{14}$ Intraoral tonsillostyloidectomy described by Eagle, which uses a transpharyngeal approach to extract the styloid process after tonsillectomy, is the treatment of choice having proven to relieve patients of styalgia. ${ }^{10}$ Its advantages include shorter operative time, absence of external scar 
and lesser risk of neurovascular injury. ${ }^{9}$ However,its disadvantages are glossopharyngeal nerve damage, inadequate ability to control haemorrhage of great vessels, increased risk of deep space neck infection and poor visualization of the surgical field (performed through open mouth). ${ }^{1}$ It is generally accepted that this approach should be used only if the distal tip of the styloid process can be palpated in the tonsillar fossa but, more importantly, only if the surgeon is familiar with the technique and handling of possible complications. ${ }^{12}$ In contrast, the external/extraoral approach performed through a large external incision, affords better exposure and vascular control, but has the disadvantages of longer operating time, cutaneous scar, longer hospitalisation, facial nerve injuries, paresthesia of cutaneous nerves such as greater auricular nerve. ${ }^{11,12,8}$ Endoscopy-assisted transoral resection circumvents the disadvantage of poor visualisation in the transoral approach, representing a favourable alternative surgical procedure and is thus recommended for treatment of patients with Eagle's syndrome, justifying its use in our case. ${ }^{8}$

As was followed in our case, certain available techniques to reduce the risk of complications are (1) maintainance of a clear surgical field by minimization of bleeding, by bipolar cauterization of small vessels before damaging them (2) endoscopy-assisted magnification of the surgical view enhances the identification of small vessels, nerves and other anatomically important structures, thereby avoiding neurovascular damage and injury to them (3) digital palpation of the styloid process to confirm its location and avoid misdirection (4) approximation of the tonsillar bed with absorbable sutures to minimize the risk of cervical infection due to sputum contamination. ${ }^{8}$

Surgical failure rate of around $20 \%$ (i.e. partial relief/ recurrence of symptoms) is due to intraoperative injury, subsequent fibrous entrapment syndrome, or inadequate shortening of the process, assuming that the diagnosis was correct in the first place. ${ }^{13}$

\section{CONCLUSION}

The aforementioned diagnostic and therapeutic methods allow physicians to correct the life-limiting conditions experienced by a patient suffering from chronic pain due to Eagle's Syndrome. Psychological effects, as in this case, can be seen, further degrading patients' quality of life. 3D-CT is the most advanced tool currently available for confirmation of this diagnosis. Endoscope-assisted transoral resection circumvents the major disadvantage of a visually contracted surgical field, thereby making this the current intervention of choice.

\section{Funding: No funding sources Conflict of interest: None declared Ethical approval: Not required}

\section{REFERENCES}

1. Kapoor J, Jindal G, Garg S. Eagle's Syndrome: A New Surgical Technique for Styloidectomy. J Maxillofac Oral Surg. 2015;14(1):360-5.

2. Murtagh RD, Caracciolo JT, Fernandez G. CT Findings Associated with Eagle's Syndrome. AJNR Am J Neuroradiol. 2001;22:1401-2.

3. Baharudin A, Rohaida I, Khairudin A. Transoral Surgical Resection of Bilateral Styloid Processes Elongation (Eagle's Syndrome). Acta Inform Med. 2012;20(2):133-5.

4. Han MK, Kim DW, Yang JY. Non Surgical Treatment of Eagle's Syndrome-A Case Report. Korean J Pain. 2013;26(2):169-72.

5. Thoenissen P, Bittermann G, Schmelzeisen R, Oshima T, Fretwurst T. Eagle's syndrome-A nonperceived differential diagnosis of temporomandibular disorder. International J Surgery Case Rep. 2015;15:123-6.

6. Müderris T, Bercin S, Sevil E, Beton S, Kiris M. Surgical management of elongated styloid process: intraoral or transcervical? Eur Arch Otorhinolaryngol. 2014;271(6):1709-13.

7. Nayak DR, Pujary K, Aggarwal M, Punnoose SE, Chaly VA. Role of three-dimensional computed tomography reconstruction in the management of elongated styloid process: A preliminary study. J Laryngol Otol. 2007;121(4):349-53.

8. Matsumoto F, Kase K, Kasai M, Komatsu H, Okizaki T, Ikeda K. Endoscopy-assisted transoral resection of the styloid process in Eagle's syndrome. Case report Head Face Med. 2012;8:21.

9. Santini L, Achache M, Gomert R. Transoral surgical treatment of Eagle's syndrome: Case report and review of literature. Rev Laryngol Otol Rhinol (Bord). 2012;133(3):141-4.

10. Naik SM, Naik SS. Tonsillo-Styloidectomy for Eagle's Syndrome: A Review of 15 Cases in KVG Medical College Sullia. Oman Med J. 2011;26(2):122-6.

11. Cawich S, Gardner M, Johnson P, Shetty R, Wolf K. The clinical significance of an elongated styloid process. Internet J Family Pract. 2007;6(1):1-5.

12. Politi M, Toro C, Tenani G. A Rare Cause for Cervical Pain: Eagle's Syndrome. International J Dentistry. 2009;doi:10.1155/2009/781297.

13. Ceylan A, Koybasioglu A, Celenk F, Yilmaz O, Uslu S. Surgical treatment of elongated styloid process: Experience of 61 cases. Skull Base. 2008;18(5):289-95.

14. Weteid AS, Miloro M. Transoral endoscopicassisted styloidectomy: How should Eagle syndrome be managed surgically? International J Oral Maxillofacial Surg. 2015;44(9):1181-7.

Cite this article as: Shilpa H, Mathew AS, Hemraj S, Sridhar A. Endoscopic transoral resection of an elongated styloid process: a case report. Int J Otorhinolaryngol Head Neck Surg 2018;4:1317-20. 